\title{
MÍDIA, JUVENTUDE E MEMÓRIA CULTURAL
}

\author{
Rosa Maria Bueno Fischer ${ }^{*}$
}

\begin{abstract}
RESUMO: O texto trata das relações entre memória, mídia e juventude. Discute os resultados de uma pesquisa com estudantes universitários e de ensino médio, sobre suas memórias culturais e midiáticas, problematizando questôes contemporâneas sobre alteridade, memória e produçóes audiovisuais, a partir de autores como Henri Bergson, Andreas Huyssen, Maria Rita Kehl e Michel Foucault, entre outros. Desenvolve-se o argumento de que a produção de sujeitos, em nosso tempo, estaria estreitamente relacionada à experiência cotidiana, em particular dos mais jovens, com as imagens e textos oferecidos pelos meios tecnológicos de informação e comunicação. Estes meios, segundo a argumentação tecida, parecem operar fortemente nos processos de elaboração de nossas memórias individuais e sociais, bem como na construção de modos de existência específicos, relacionados à construção de nós mesmos e de nossas diferenças.
\end{abstract}

Palavras-chave: Juventude. Memória. Cultura. Mídia. Alteridade.

\section{MEDia, YOUTH AND CULTURAL MEMORY}

ABSTRACT: This text aims to discuss relations between memory, media and youth. I discuss dates from a research with Brazilian students about their cultural memories, alterity and audiovisual products in our culture. Theoretical references are concepts from Henri Bergson, Andreas Huyssen, Maria Rita Kehl and Michel Foucault. I put forward the argument that production of subjectivity, in our times, is narrowly related to the experience with images and texts

Doutora em Educação e professora do Programa de Pós-Graduação em Educação e do Curso de Pedagogia da Universidade Federal do Rio Grande do Sul (Ufrgs). E-mail: rosabfischer@terra.com.br

Educ. Soc., Campinas, vol. 29, n. 104 - Especial, p. 667-686, out. 2008 
from different media. Technologies of communication and information offer an important source to memories construction, in order to shape our lives and our differences.

Key words: Youth. Memory. Culture. Media. Alterity.

\section{Mídia, juventude e memória cultural}

E

ste texto ${ }^{1}$ trata de questões relativas à produção, veiculação e consumo de imagens, focalizando a atenção na memória de jovens de 15 a 24 anos, em nosso tempo, sobre sua experiência com imagens, sons e textos das mídias. ${ }^{2}$ Para tanto, opero aqui com um conjunto de conceitos, a começar pelos de imagem e memória, que articulo aos de alteridade, mídia e juventude. ${ }^{3}$ As perguntas que moveram o estudo maior, sobre algumas das quais aqui discuto, podem ser assim sintetizadas: Como nossa sociedade tem distribuído espacialmente os diferentes tipos de jovens e de que modo eles mesmos, na condição de homens e mulheres, referem-se a si mesmos? Como avaliam as formas de nomeação do jovem pela indústria cultural nestes últimos quinze anos? $\mathrm{O}$ que afirmam e como se pode pensar o que dizem sobre as formas como as diferentes mídias, das mais simples às mais sofisticadas, em termos das tecnologias utilizadas, os têm construído? E, mais especificamente, como articulam suas memórias, individuais e coletivas, à sua experiência com produtos da publicidade e da cultura audiovisual?

Nossas perguntas, pensando a partir da palavra de Skliar (2003), caminharam por várias espacialidades, como diria o autor: estaríamos narrando o jovem como um "outro" colonizado, como alguém que vem se tornando uma espécie de objeto exótico de desejo e curiosidade? E como pensar a "adulação" de que fala Bauman (2001), desse convite a uma espécie de ditadura jovem em nossa cultura? Ainda: os jovens "diferentes", cada vez mais contemplados na mídia e na publicidade, estariam sendo acolhidos como "diversidade multicultural" ou na sua condição de diferença mesmo, como outros irredutíveis, completo mistério, "différance" (Derrida \& Roudinesco, 2004)? Finalmente (e não menos importante): como esses jovens narram sua experiência com o tempo presente, passado e futuro, tendo como centro de atenção as imagens pelas quais as diversas gerações, especialmente a deles mesmo, os têm inventado? 
De acordo com Zizek (2003a), vivemos um tempo em que grandes e sérios conflitos econômicos e políticos passam a ser deslocados para o terreno da cultura: se as diferenças são inúmeras e constatáveis, como a da radical cisão entre ricos e pobres, é bem verdade que o interesse maior hoje parece centrar-se predominantemente no reconhecimento das diferenças culturais - fato que, para o autor esloveno, não deveria constituir-se como "o último horizonte da política": "Para reconhecer você como diferente, nós devemos partilhar um campo mínimo de solidariedade. Sem isso, a diferença não é interessante para o pensamento. A diferença não vem primeiro" (p. 6). Ora, esse argumento nos interessa de modo particular, pois, como Zizek, entendemos que o debate teórico a respeito das diferenças - e dos modos como elas são nomeadas pelos meios de comunicação contemporâneos - não pode ser desvinculado de uma atitude e de um agir políticos.

\section{Fetiches e sintomas de imagens midiáticas}

Falar de formas de uma espécie de "alteridade jovem", em relação às narrativas midiáticas e à memória das imagens a respeito desses meios, exige que articulemos conceitos de áreas diversas do conhecimento. Marilena Chauí, no prefácio ao livro Videologias, de Eugênio Bucci e Maria Rita Kehl (2004), anuncia que os autores buscam em seus ensaios falar do modo de produção do imaginário contemporâneo, nos meios audiovisuais, e o fazem a partir da "crítica da imagem enquanto imagem, seja no nível do inconsciente individual, seja no nível do inconsciente coletivo" (Chauí, 2004, p. 12, destaque da autora). Atualizando para nosso tempo o conceito de fetichismo (na psicanálise freudiana e na teoria marxista da mercadoria), os autores do livro Videologias oferecem farto material sobre nossas relaçóes com os produtos das tecnologias da comunicação e da informação; o fetichismo, hoje, insere-se na sociedade do espetáculo e do consumo, "na qual o gozo e a satisfação se tornaram imperativos sociais e morais" (idem, ibid., p. 13).

Busco esses autores, associando a discussão sobre alteridades, diversidades e diferenças aos temas da juventude e das práticas da indústria cultural e da sociedade do espetáculo. Procuro pensar "o outro jovem" na sua relação com a mídia, tendo como preocupação o olhar atento àquilo que Marjorie Garber chamou de "sintomas da cultura", 
no livro Symptoms of culture (1999). Do ponto de vista da psicanálise, a autora nos sugere que leiamos aquilo que "fala" na cultura, já que sintomas são modos de falar de algo que existe como doença. A proposta é "ler a cultura" como se ela fosse estruturada qual um sonho, qual uma rede de imagens, relacionadas a desejos, medos, projeçôes, identificaçôes, e cujos elementos estão solidamente fundados em bases sociais, políticas e econômicas muito concretas (Garber, 1999, p. 8-9).

A cultura do medo e da violência, por exemplo, poderia ser vista como um sintoma de nossa cultura; refiro-me a esse sintoma, rapidamente, já que foi um dos temas recorrentes lembrados pelos jovens pesquisados, não só nos debates como nas respostas aos questionários. E não por acaso também é um dos temas insistentemente tratados pelos meios de comunicação. Concordo com Jurandir Freire Costa: o sentimento de desamparo, a exposição permanente à violência e às narrativas midiáticas que tematizam o medo de todos nós precisam ser analisados de modo a estabelecer relações com as formas pelas quais tratamos e nomeamos os outros. Assassinatos, atos de crueldade de toda ordem, humilhações, agressões físicas e psicológicas, embora sejam considerados indesejáveis, podem também passar a ser facilmente aceitos: "Basta desumanizar o próximo. Basta acreditar que ele não é um sujeito moral como 'nós' para que a crueldade cometida não seja percebida em seu horror" (Costa, 1994, p. 123).

Jornais, canais de televisão, emissoras de rádio não se cansam de narrar jovens envolvidos em casos de violência, e é muito clara a cisão vislumbrada a cada texto, a cada imagem, a divisão entre "nós" e "eles", entre os jovens de classe média, brancos, universitários ou estudantes de uma boa escola particular e aqueles que desumanizamos, que literalmente consideramos inferiores. Falo aqui de juventude, de mídia, de diferenças. O importante a pensar, nessa perspectiva, é que os jovens, de uma maneira geral, em relação à ordem midiática, do mercado e da sociedade do espetáculo, estariam permanentemente "de fora", embora constantemente sejam interpelados por essa mesma ordem. Este seria o grande fantasma: ficar de fora, fora do consumo, fora da fama, fora da moda, fora da publicidade. Para ficar "por dentro", a saída parece ser esta: inscrever-se como um "novo tipo de objeto", ausente de deliberações éticas, fixado num tipo de narcisismo para o qual valem exclusivamente os interesses individualistas (Costa, 1994, p. 124-125). 
Real, simbólico e imaginário: ferramentas para ler a cultura

No livro Bem-vindo ao deserto do real!, Slavoj Zizek (2003b) nos ajuda a estabelecer melhor ainda essas relaçôes que aqui expomos, entre mídia, diferença e juventude. As análises do pensador esloveno incursionam pelo universo na publicidade, do cinema, da televisão. Com fundamento na filosofia de Hegel e na psicanálise de Lacan, ele nos fala de um mundo que estaria fascinado, entregue à "paixão pelo real", expressão que Zizek toma de Alain Badiou, como nos lembra Kehl (2004), comentando passagens dessa obra. Penso que o tripé lacaniano dos registros do real, do simbólico e do imaginário, utilizado por Zizek em suas análises da cultura, mostra-se extremamente útil e necessário aqui. Como escreve Kehl (op. cit., p. 12), o "real é o elemento traumático que resiste a ser integrado simbolicamente na vida social e/ou na realidade psíquica". De certa forma, nunca temos acesso ao real, precisamos simbolizá-lo; a palavra, as imagens, a poesia, as narrativas, os sonhos também, todos são meios de buscar o acesso ao real. Como esse pleno acesso é impossível, somos levados à repetição da narrativa (de pesadelos, de histórias horrendas, de violências que vivemos etc). Só que essa paixão pelo real, diz Kehl, está diretamente relacionada aos imaginários que se produzem no social; ela é, nas palavras da psicanalista:

A força propulsora das formações imaginárias que recobrem todos os aspectos da vida que não podemos compreender. É precisamente do imaginário que se alimenta a ideologia. Aliada a todas as formas de gozo, tal paixão gera o impulso cego que nos precipita, em ato, a intervir diretamente sobre o real, nos casos em que todo o campo simbólico parece estar tão perfeitamente recoberto pelo imaginário que nenhuma mudança substancial parece possível. Esse é o paradoxo da paixão pelo real: ela é alimentada pelas formações do imaginário, que no caso contemporâneo são produzidas na escala superindustrial do espetáculo globalizado. (Idem, ibid.).

Não é no campo do imaginário que outras interpretações são possíveis e necessárias, mas sim no campo do simbólico, daquilo que está para ser nomeado, seja como arte, seja mesmo como lei: num caso como no outro, trata-se de arranjos sociais, de possibilidades, de jogos de linguagem específicos. Escrever, produzir poesia e literatura, pintar, 
desenhar, fazer música, dançar, fazer cinema estariam na ordem da invenção, da criação de falas novas, faz parte daquilo que Bauman (2001) chama de "estratégias de transcendência", ou, como escreve Kehl (2000, p. 238), ${ }^{4}$ seria um modo de abrir uma brecha na "pedra dura do real, adiando temporariamente nosso confronto inevitável com a morte". Os produtos da indústria cultural, massivamente consumidos, massivamente elaborados, pertenceriam a essa ordem também? Talvez sim. Mas pertencem à ordem simbólica de um modo muito particular, na medida em que investem poderosamente na produção de uma infinidade de sentidos, procurando recobrir todos os "buracos", todas as faltas - as quais exatamente são propulsoras de buscas de sentido e de produções simbólicas. $\mathrm{Na}$ medida em que tudo está recoberto de imaginário, em que o imaginário social efetivamente "excede", abre-se o caminho para ações extremamente violentas, para atos de tentativa de acesso puro ao real.

Matar e morrer, no caso de tantos jovens neste país, são atos que parecem estar vinculados a isso, e ao que Jurandir Freire Costa (1994) afirma sobre ausência de idealidade de si, de reconhecimento de si no mundo social, no seu tempo (do tipo "eu sou alguém aqui"), e que por isso não permite a esses sujeitos reconhecerem no outro (a quem assaltam ou ferem) alguém como eles mesmos, da mesma forma que o policial não o reconhece como gente. Ora, a meu ver isso está relacionado com imaginários produzidos socialmente e que circulam todos os dias nos meios de comunicação: ali também aprendemos quem existe e quem não existe, quem é reconhecido e quem não tem nome, quem é o diferente exótico, quem é a personalidade a ser incensada, quem tem e quem não tem, quem pode ter ou quem jamais poderá ter. ${ }^{5} \mathrm{Ali}$ ás, o tema da morte e da violência, na voz dos estudantes pesquisados, muitas vezes vem associado a temores em relação a catástrofes possíveis, especialmente as ambientais - outro assunto do qual nenhum dos meios de comunicação se abstém de falar, cotidianamente.

Sem perder de vista o mergulho em conceitos específicos - como o de imagem, por exemplo -, como veremos adiante, interessa-me, a propósito dos dados aqui discutidos, mostrar a importância de estudar mídias e tecnologias em relação à educação, em articulação com questões de ordem política, como, por exemplo, as levantadas por Arendt (2000). Segundo escreve Ortega (2000, p. 24), a filósofa entende que pensar em 
termos políticos "representa uma tentativa de pensar o acontecimento, de afrontar a contingência, de romper e inaugurar, de recusar as imagens e metáforas tradicionais oferecidas para imaginar o político e uma vontade de agir, de transgredir e superar os limites". As contingências do mundo do espetáculo, dos novos fundamentalismos, do narcisismo associado à cotidiana exclusão de muitos "outros" efetivamente existem, mas não conduzem necessariamente a uma paralisação. A escuta das memórias jovens, de que falo aqui, inscreveu-se, portanto, no desejo de transgredir e imaginar novos modos de experiência pública.

\section{Memória, tempo e criação}

Além desses referenciais sobre alteridade e produção simbólica na cultura, comentados acima, recorro - como Eclea Bosi (1987) o fez em seu Memória e sociedade: lembranças de velhos - ao filósofo Henri Bergson, para sustentar a escuta que fiz de jovens porto-alegrenses, a respeito de sua breve memória sobre um tipo muito particular de experiência: a relação com imagens publicitárias e midiáticas. Ora, sabemos que a filosofia de Bergson se constrói a partir da intuição como método: não a intuição romântica do senso comum, mas a intuição que busca expressar-se, que busca penetrar até a profundeza do real e extrair dela, por meio de imagens, o que os conceitos são impotentes para revelar em toda a sua plenitude. É o método intuitivo que permitiria descobrir, nas operações psíquicas, as características da duração (já que o tempo sempre é um tempo concreto), da qualidade (o psíquico é irredutível ao quantitativo e ao mecânico) e da liberdade (na medida em que o psiquismo consiste em criação perpétua). Matéria e memória, espacialização e temporalização, para o filósofo, seriam exemplos de como o real se oferece sucessivamente à inteligência e à intuição. Em Matéria e memória, Bergson (1990, p. 197) escreve que

(...) nosso presente não deve se definir como o que é mais intenso: ele é o que age sobre nós e o que nos faz agir, ele é sensorial e é motor; nosso presente é antes de tudo o estado do nosso corpo. Nosso passado, ao contrário, é o que não age mais, mas poderia agir, o que agirá ao inserirse numa sensação presente da qual tomará emprestada a vitalidade.

O importante é esse movimento, do presente ao passado e do passado ao presente; Bergson diz que não se trata, na memória, de uma 
regressão ao passado, mas de um "progresso do passado ao presente" (p. 196). Trata-se de um estado de "virtualidade" do passado, algo que vai sendo conduzido, por uma série de "planos de consciência diferentes”, até materializar-se numa percepção atual, presente, atuante em nosso próprio corpo (idem). Segundo Bergson, portanto, nosso próprio corpo é imagem: ele não "armazena" imagens, ele mesmo é parte constitutiva das imagens, pois elas "estão" nele. E é do presente que emanam os apelos em direção às nossas lembranças. Nesse sentido, segundo o filósofo, viver exclusivamente no presente seria pouco para o homem, seria viver na impulsividade apenas; ao mesmo tempo, viver no passado seria próprio dos sonhadores. O ponto ideal, em relação a nosso trabalho com a memória, seria estarmos atentos às situações presentes, de modo a vê-las em maior profundidade e de forma seletiva, no sentido também de uma ação crescente de organização de nossas lembranças.

Considero que a filosofia de Bergson sobre memória e intuição, também sobre os conceitos de objetividade e subjetividade (objetividade como o dado, o que não se caracteriza como virtualidade; e subjetividade como aquilo que pode atualizar-se, que devém, que pode vir a ser), enfim, sobre a noção de "virtual" - que funda toda uma filosofia da memória e da vida, conforme explicita Deleuze (1999), em Bergsonismo - mostra-se como elemento básico para pensar os dados sobre a memória cultural e midiática de jovens em nosso tempo.

Associamos neste trabalho as formulações de Bergson às do estudioso alemão Andreas Huyssen $(1997 ; 2000)$, sobre as relações entre memória, sociedade e mídia, problematizando a recordação como uma construção social, evocada por demandas e materiais simbólicos dados pelo presente, com ênfase no papel dos meios de comunicação. Huyssen nos auxilia a pensar os processos históricos e sociais de construção das nossas lembranças, afirmando que a obsessão pela memória, vivida nas últimas décadas em nossa cultura, está diretamente relacionada ao bombardeio de informaçôes a que somos submetidos e, conseqüentemente, ao medo do esquecimento. Tais atitudes caminham exatamente na contramão daquilo que propõe Bergson, como vimos acima. "Nostalgia é a lei que move o mundo", diz um estudante universitário de 18 anos, referindo-se ao boom de festas e eventos relacionados à rememoração dos anos de 1980. Outro jovem de 16 anos, do ensino médio, complementa: “Às vezes tu esquece de tudo, então tu pegas 
aquela caixinha ali, de recordação, e acaba te lembrando (...). É tão bom...". Ora, hoje temos acesso não só às nossas "caixinhas" de recordação, mas a todo um aparato tecnológico, de vídeos, DVDs, sites especializados, verdadeiros acervos de memórias reais.

Huyssen $(1997 ;$ 2000), então, nos ajuda a entender o paradoxo dos depoimentos dos jovens - amarrados ao presente, mas idealizando o passado dos pais; angustiados com a falta de tempo, mas deliciados com a instantaneidade e a rapidez da comunicação. Para o estudioso alemão, o real pode fazer-se mítico, assim como o mítico pode imiscuir-se na vida cotidiana, produzindo efeitos importantes na chamada realidade. E é disso exatamente que se trata, quando observamos a riqueza e a complexidade dos depoimentos dos estudantes sobre o tempo, a memória e as novas tecnologias.

\section{Uma palavra sobre olhar e imagem}

Em toda a discussão que vimos fazendo até aqui, de certa forma já anunciamos um posicionamento a respeito do conceito de imagem, que não se separa do conceito de memória, como veremos. Assim como Bergson insiste em que corpo e imagem não se separam, outros estudiosos, como Didi-Huberman e Marilena Chauí, chamam a atenção para a necessidade de ultrapassarmos as visões clássicas do ato de ver (que remete necessariamente ao conceito de imagem), ora situando-o nas "coisas", ora na ação soberana do sujeito que, ao olhar, "iluminaria" o objeto. Fabiana de Amorim Marcello (2007) escreve, a respeito da cisão do olhar, valendo-se de Didi-Huberman:

(...) o filósofo discute acerca dessa "inelutável cisão do ver" e nos convida: "devemos fechar os olhos para ver quando o ato de ver nos remete a um vazio que nos olha, nos concerne e, em certo sentido, nos constitui" (ibidem, p. 31). Afastamo-nos, portanto, de uma crença que sugeriria que a visão depende de nós. Ao enfatizar que o que está diante de nós também nos olha, o autor, de algum modo, rompe com o subjetivismo do olhar (mais propriamente, daquele que olha), que acreditaria, por exemplo, conseguir tornar as coisas inexistentes pelo simples fato de fechar os olhos. (Marcello, 2007, p. 2)

Em outras palavras: ao nos depararmos com imagens (e aqui nos interessam especialmente aquelas veiculadas pelo cinema, pela TV e todos 
os meios audiovisuais), sempre haverá uma espécie de perda (no ato de olhar): qualquer imagem se nos apresenta como incompleta, mesmo que haja um esforço por fazê-las plenas de sentido, ou por tentar cobrir todos os seus buracos - como sucede costumeiramente com diferentes materiais publicitários ou com produçōes do tipo oferecido pelo "cinemão hollywoodiano". Até essas produções, quando submetidas a um olhar investigativo e suscitador de debate - como na experiência que tivemos nos grupos de recepção da pesquisa aqui comentada -, podem aparecer nos seus vazios, nas suas incompletudes. Como lembra Marcello, essa é a posição de Didi-Huberman, quando este afirma que as imagens "nos olham": ao olhar algo, tocamos também um pouco desse vazio das imagens, e nesse momento algo sempre nos foge. "E, por isso, tal cisão é inelutável: queiramos ou não, algo nos escapa no ato mesmo de ver, algo que nada tem de evidente" (Marcello, 2007, p. 2).

O mesmo Didi-Huberman, no livro Imágenes pese a todo, analisando fotos de anônimos sobre o horror de Auschwitz (o crematório V), chama a atenção para a importância de tais registros, "em que pese" a impossibilidade de nessas imagens "dizer-se tudo". Elas se dirigem ao inimaginável, escreve Didi-Huberman (2004, p. 37), e ao mesmo tempo o refutam. Daí a importância de vê-las e de pensar a partir delas. Insistir no inimaginável é des-historicizar as singularidades dos acontecimentos; insistir no inimaginável também é aderir a um esteticismo sem história (idem, p. 50). Em contraposição, aceitar o "duplo" das imagens e do ato de ver significa pensar na "verdade" a que elas podem remeter, bem como na permanente obscuridade de que elas são feitas. Trata-se de exercer a observação, entregar-se às imagens, saber delas e dá-las a conhecer, organizá-las de um determinado jeito - mesmo que elas sejam para sempre fugazes, incompletas, móveis. É o que nos ensina DidiHuberman, sustentando a tese de que a imagem está no centro também de uma questão ética. Cabe então a pergunta: Afinal, o que precisamos recordar, que imagens são fundamentais para atuarmos eticamente em nosso tempo? (idem, p. 232). Sabemos que as imagens não ressuscitam mortos, não nos redimem, nem nos consolam. Mas tratar delas seria, mesmo que momentaneamente, levantar o véu que as cobre - deixandoas dizer algo sobre o mundo e sobre nós mesmos -, sabendo ainda assim que nesse mesmo ato ela volta a cobrir-se, indisponível a uma total leitura (idem, p. 247). 
"Que todo mundo entre então no jogo das imagens e se ponha a jogá-lo", escreve Foucault, no texto "A pintura fotogênica", no qual analisa o trabalho do artista Fromanger. Foucault (2001, p. 353) reivindica não "a" imagem, mas o acontecimento, aquilo que seria interior à imagem, um acontecimento que é sempre único, aquilo que é, sobretudo, "passagem". Ora, nos inúmeros textos de Foucault sobre artes visuais, ele propõe que o fato de algo se fazer visível, em pinturas ou outras imagens, atestaria justamente sua desvinculação em relação a qualquer realidade. Um filme, uma fotografia ou uma escultura - esses próprios objetos configuram-se como "realidades". Assim, nosso afã em retratar, refletir ou imitar é inócuo, pois estamos sempre diante de invisibilidades profundas e da impossibilidade de fazer com que algo se torne efetivamente presente (idem, p. 209). Isso não quer dizer, de maneira alguma, que esses objetos visuais que criamos ou a que temos acesso, na cultura, não sejam históricos e passíveis de uma análise. $\mathrm{O}$ que importa é essa complexidade das imagens, esse jogo permanente entre o visível e o invisível, do qual precisamos dar conta, se desejamos tratar da vida como acontecimento, e pensar as coisas ditas e mostradas para além do grande modelo da representação, do "isto representa aquilo", "isto esconde aquilo". ${ }^{6} \mathrm{O}$ não-isomorfismo entre ver e falar, entre o visto e o falado, entre a palavra e a coisa - essa é a proposta de Didi-Huberman; essa é a proposta de Foucault, que aqui assumimos, quando tratamos das imagens e memórias midiáticas de grupos jovens em nosso tempo.

\section{Imagens do "meu tempo"}

Com base nas provocações desses autores, passo a discutir tópicos tratados ao longo de três anos da pesquisa aqui referida. Nos levantamentos feitos sobre alteridade jovem e memória cultural midiática, várias questôes foram levantadas, não apenas por meio dos questionários, mas especialmente pelos debates, tanto nas escolas públicas e privadas de ensino médio, como em dois cursos da UfRgs (calouros de Pedagogia e Psicologia). Buscamos basicamente problematizar o seguinte: Como os jovens, de diferentes camadas sociais, se relacionam com os imaginários da grande mídia? Como estabelecem relações desse imaginário com o real cotidiano e como manifestam possibilidades de fuga, de resistência, a partir de experiências genuínas de simbolização? A partir 
de que gestos eles marcam presença, ou seja, de que modo deixam para os outros a sua palavra, e como aprendem a ver-se como semelhantes na diferença? Ainda: Como se narram para além das formações imaginárias da mídia sobre adolescentes, teenagers, jovens? Finalmente: De que maneira aprendem e expressam relaçōes entre o desejo de marcar uma possível singularidade e a necessidade crucial de "estar-com" o outro, com aqueles que poderíamos chamar de iguais-diferentes? ${ }^{7}$

Em primeiro lugar, foi possível observar a forte presença, em suas rememoraçôes desde a infância, de objetos, situaçôes e personagens originados dos meios de comunicação, especialmente da música, do cinema e da televisão, das histórias em quadrinhos, além de brinquedos, guloseimas e jogos diversos; nessas rememorações, vale ressaltar, a memória de peças publicitárias é uma constante. Impossível não referir aqui o romance de Umberto Eco, A misteriosa chama da rainha Loana, em que o personagem Yambo perde a memória num acidente e, na recuperação, vê-se às voltas com um sem-número de imagens recentes e antigas, a maioria relacionada à sua experiência com as mídias, a publicidade e os jogos eletrônicos. Nas primeiras páginas do romance, o personagem diz: "Sei o que é um fliperama. Mas não sei quem sou eu, entende?” (Eco, 2005, p. 22); páginas depois, o homem em recuperação se vê diante de um gibi de Walt Disney e reconhece cada trecho da história em quadrinhos, vai direto aos quadros certos e recita de memória toda a narrativa. A mulher indaga: "Como você pode saber tudo isso?". Ele responde com uma pergunta: "Todo mundo sabe, não?" (idem, ibid., p. 75).

Trata-se no romance de Eco de uma situação limite, de perda da memória, mas ela nos remete ao grande tema das perdas e ganhos, neste tempo de excesso de informação (mais dados, mais "conhecimento", mais acesso a quase tudo; por outro lado, sensação de vazio, dificuldade de escolhas); também nos leva a pensar sobre as tênues fronteiras entre aquilo que é da ordem de nossos repertórios individuais e aquilo que é da ordem do coletivo. No caso do personagem Yambo, discos, quadrinhos e jornais emergem, recompondo o período fascista na Itália e todos os horrores da Segunda Guerra Mundial.

Nossos estudantes, por seu turno, ao debaterem conosco, estabelecem inúmeras associações de suas memórias com sentimentos e vivências, sociais ou individuais; semelhante ao personagem de Eco. 
Seus depoimentos marcam o tempo (“antes", "depois", infância, adolescência, primeira relação amorosa, primeiro emprego, casamento, entrada na vida adulta, primeiro filho), quase sempre a partir de objetos de consumo, os quais aparecem articulados a personagens de diferentes produtos das mídias.

Talvez o dado mais surpreendente tenha sido a constatação de certo "saudosismo precoce", presente já há algum tempo em materiais da internet que circulam entre pessoas e grupos de faixas etárias diversas. Enviam-se questionários os mais diversos, pela rede de computadores, a partir dos quais se busca testar o pertencimento das pessoas a uma determinada geração. Inevitavelmente, as referências são relativas a objetos de consumo (par de tênis da marca tal), a ídolos da música pop, ao uso de certo vocabulário, a um filme ou a um programa de TV, a heróis de gibis, a uma determinada composição musical. Estudantes de 15 a 16 anos, assim, tranqüilamente repetem a expressão "no meu tempo...", como se fossem já pessoas maduras e saudosas de uma juventude vivida "anos atrás". Vive-se aí um prazer compartilhado, de sentir-se pertencendo a uma determinada "tribo" (dos anos 90, dos anos 80, tão "distantes"). Simultaneamente, eles expressam angústia com o "pouco tempo" de que dispõem; da mesma forma, em muitos depoimentos a idéia de "fazer alguma coisa" vem necessariamente associada a "fazer alguma coisa produtiva". Nesse sentido, ver TV, comunicar-se pela internet, jogar no computador, tudo isso é percebido como "não fazer nada".

A pesquisadora italiana Carmen Leccardi, especialista em estudos sobre juventude e tempo, remete-se a Norbert Elias para lembrar que a consciência temporal e os modos de concebermos e vivenciarmos o tempo não é nem um dado biológico, nem um dado metafísico, mas plenamente social, cultural (Leccardi, 2005). Os jovens de nossa investigação acabam por oferecer um panorama de sentimentos por vezes contraditórios, em relação ao "uso do tempo": as tecnologias digitais, o uso de aparelhos como MP3, telefones celulares e, especialmente, a comunicação via sites de relacionamento fazem-nos ocupar excessivamente o tempo, na mesma medida em que essas práticas são desejadas (especialmente pelo prazer da instantaneidade) e relacionadas a um "nada fazer". "A gente se acostuma a fazer tudo rápido (...), não tem o stress de ficar lá procurando [informaçôes] em jornal e revista", diz uma jovem de 16 anos, estudante de escola pública estadual. A mesma aluna 
conta que fica de duas a seis horas por dia navegando na internet. E conclui: "aí eu não faço nada, praticamente".

Eles referem que vêem televisão de duas a quatro horas por dia; essa prática associa-se ao "vício" (como eles dizem) de entrar nas comunidades como o Orkut ou o MSN, muitas vezes para comunicar-se com pessoas muito próximas, com quem eles têm contato presencial, diariamente. Tais práticas aparecem associadas a uma curiosa percepção do tempo: um tempo que parece encurtar a cada dia, de tal modo que jovens de 15 ou 18 anos referem-se a si mesmos como pessoas que literalmente "não têm tempo", sentem-se "divididos" e fragmentados. A maioria deles revela certa angústia com o tempo, que para todos eles passa rápido demais - angústia que não se separa de outro problema: a necessidade quase incontrolável de estar up to date com a mais nova tecnologia (do celular, do PC, do programa de download de músicas e materiais audiovisuais etc.), como se todas as coisas no mundo envelhecessem a cada segundo.

Para completar esse quadro, contraditoriamente ou não, a maioria dos estudantes que pesquisamos, mesmo afirmando "viver o presente" (ou consagrando-se ao instante, como escreve Canclini [2005]), manifesta uma percepção mítica do passado, particularmente da juventude dos pais. Segundo eles, seus pais, sim, "sabiam" participar politicamente, tinham ídolos interessantes, como filósofos e artistas, criativos e engajados em lutas sociais. Alguns revelam até certo apego às imagens e aos modos de pensar, de épocas não vividas por eles. Há para outros o prazer de referir-se a produtos do cinema, da literatura ou da TV a que tiveram acesso na relação com os pais, materiais que seriam mais "eruditos" (apreciar um clássico do cinema francês ou ouvir Chico Buarque é comentado com certo orgulho). Porém, na maioria dos casos, o que se observa é uma reduzida experiência com materiais audiovisuais que estejam fora do circuito massivo da produção hollywoodiana, veiculada nos canais de TV, a que eles têm acesso também nos cinemas e nas videolocadoras. Em todos os grupos e na maioria das respostas aos questionários, por exemplo, o filme norte-americano American pie $^{8}$ aparece como a lembrança mais recorrente, tanto para estudantes de 15 a 16 anos como para universitários de 22 a 24 anos de idade.

Veja-se, a propósito, este depoimento de uma estudante de Psicologia, de 19 anos: "As pessoas tão revoltadas com o mundo, acho que 
as pessoas vêem que é uma sociedade bastante doente, tem bastante problema, aí tentam voltar ao passado... Aí voltam a esses anos 70, 80, de uma forma romantizada, achando que tudo era bom naquela época, aí pensam, por exemplo, na ditadura militar, que tinha gente que lutava contra. Aí é o romantismo daquelas pessoas... Ah, aquelas pessoas que fizeram esse país. Ah, eu queria ser igual a eles...”.

\section{Mais perguntas}

Tratei aqui da memória cultural jovem, discutindo alguns dos resultados de investigação feita com estudantes de ensino médio e universitário, na cidade de Porto Alegre. Foi possível mostrar na pesquisa o lugar dos meios de comunicação (e das tecnologias digitais, de maneira mais ampla) como lugar por excelência de construção e veiculação de uma série de "verdades" - no caso que nos interessa, verdades sobre infância e juventude, com repercussões indiscutíveis para as práticas educacionais e para a formação dos mais jovens. Essa constatação referenda reflexôes de teóricos como Zigmunt Bauman (2001), Slavoj Zizek (2003b), Jurandir Freire Costa (2004), Roger Silverstone (2002), entre tantos outros, que apontam para o fato de que os meios de comunicação e agora a internet têm se apresentado, cada vez mais fortemente, como o grande espaço de expressão do privado e do público - duas esferas que se entrecruzam de modo espetacular, como refere a pesquisadora Beatriz Sarlo (1997a; 1997b), alterando significativamente nossas percepçōes de política, ética e estética. Neste texto, tratei especificamente de questóes relativas à memória cultural dos jovens pesquisados, bem como às suas mais significativas inquietações sobre presente, passado e futuro.

A reafirmação do senso comum, por alguns dos estudantes ouvidos, de que os jovens seriam hoje apáticos e desinteressados pelas causas sociais e políticas poderia ser articulada aos depoimentos, em que se pode comprovar a íntima relação entre o que Lucia Rabello de Castro (Castro \& Correa, 2005) chama de "trabalho psíquico de construção individualizada de si" e a "reconfiguração do coletivo". ${ }^{9}$ Há crítica ao mundo em que vivem, na fala dos entrevistados; e o apego ao passado mítico dos pais pode ser entendido também como desejo de "fazer alguma coisa", de não se ver simplesmente como um "sintoma da cultura”, conforme escreve Maria Rita Kehl (2004), a respeito da juventude 
contemporânea, uma juventude enaltecida por seu corpo e vitalidade, mas nem por isso alijada das diferentes formas de exclusão - desemprego, ociosidade, mortes violentas, e assim por diante (Castro \& Correa, 2005).

Assim, a sensação de vazio, relatada em muitos dos depoimentos, talvez não esteja apenas relacionada ao uso do tempo, à angústia quanto à rapidez e à instantaneidade de comunicação, permitidas pelas novas tecnologias. As dificuldades de vivência com o mundo adulto também seriam responsáveis por essa sensação de "nada" - um nada que, aliás, é rapidamente preenchido pela competente ação das grandes mídias, do mercado e da publicidade (Kehl, 2004), atentas à desejada e idealizada figura do corpo jovem. Por outro lado, a "musealização da cultura", como refere o teórico Huyssen (2000), também participaria, a meu ver, desse preenchimento de vazios, evidenciando uma necessidade de guardar, de reter o tempo e as coisas, por medo do esquecimento.

Nas pesquisas anteriores e nesta que aqui comentamos, as análises mostram a forte presença da imagem jovem, na maioria dos materiais midiáticos que circulam em nossa sociedade, de revistas a programas de rádio e TV, além do cinema e da internet. Mas essa presença não parece ser uma resposta suficiente às aspiraçôes de jovens de 15 a 24 anos, quanto ao acesso a produtos e práticas culturais. Há a expressão de um desejo não atendido, observado a partir de diferentes pesquisas: o desejo de participar, de estar presente, de envolver-se, por exemplo, com arte, cinema, vídeo, teatro, com formas de expressão de si mesmo, com materiais que arrebatem esses jovens para algum outro tipo de inscrição no social.

Em outras palavras: ao empreender a análise dos dados coletados, acabamos por formular novas perguntas, que deixamos ao leitor na conclusão deste artigo. Haveria uma relação entre o repertório audiovisual dos jovens de nosso tempo e a sensação de vazio e insatisfação que manifestam? Um repertório feito de comédias românticas, filmes "de ação", materiais marcados pela linguagem do chamado "cinemão hollywoodiano", poderia estar associado a um sentimento de não pertencimento, de falta, de vazio quanto ao acesso às próprias salas de projeção, à apresentação de espetáculos de teatro e de dança, à aquisição de livros, e assim por diante? Estaria certa a psicanalista Maria Rita Kehl, ao falar de um "excesso de imaginário", segundo o qual estaríamos sendo 


\title{
imaginados, nomeados e narrados a todo o momento, sem efetivamente encontrarmos espaços para nos inscrever no social?
}

\author{
Recebido e aprovado em agosto de 2008.
}

\section{Notas}

1. Refiro-me aqui à pesquisa "Alteridade e cultura midiática: memórias de juventude", realizada de 2005 a 2008. Agradeço ao CNPq pelas bolsas de Produtividade em Pesquisa e de Iniciação Científica, nesse período. Agradeço também, de modo especial, aos bolsistas Gustavo Andrade Bandeira, Fabiana Silva Wetsphalen, Lisandra Eick de Lima, Letícia Germano, Ananda Hilgert e Fernanda Heberle.

2. Realizamos na pesquisa 21 encontros com um total de 150 alunos, com idade entre 15 e 24 anos, reunidos em seis grupos de recepção: alunos de ensino médio de duas escolas públicas, duas escolas particulares e dois grupos do ensino superior (dos cursos de Psicologia e de Pedagogia, da UfRGS), nos anos de 2006 e 2007. Em média, houve três encontros com cada grupo, nos quais debatemos temas relativos à memória cultural dos jovens, suas preferências em relação a produtos dos meios de comunicação e suas ponderaçôes e questionamentos sobre o tempo e as novas tecnologias. As sessões com os grupos foram gravadas em vídeo. Além disso, esses mesmos grupos responderam a um questionário sobre consumo cultural, concepçōes de juventude e relação com o tempo, aplicado a outros 220 estudantes da Grande Porto Alegre.

3. Utilizamos aqui o conceito de juventude presente em vários trabalhos, como os publicados pela Fundação Perseu Abramo, sobre o Projeto Juventude, especialmente no livro $J u$ ventude e sociedade - trabalho, educação, cultura e participação (Abramo \& Branco, 2005).

4. A psicanalista Maria Rita Kehl escreve essa frase a partir de uma citação de Gean Genet, e a propósito da análise que faz das músicas e letras do grupo rapper MC Racionais, no texto "A fratria órfā" (Kehl, 2000).

5. A propósito desse tema da construção do outro nas mídias, ver Fischer (2008).

6. Ver, a propósito da análise dos enunciados, em Foucault, a discussão da impossibilidade de chegar à "verdade" dos discursos, em Fischer (2001).

7. Ver, a propósito, a passagem da belíssima análise de Maria Rita Kehl, sobre as composições do grupo MC Racionais, onde a autora relata um evento em que os rappers desse grupo incluíram mulheres (quase sempre excluídas): "A inclusão desse outro tão diferente, mas com quem se pode compartilhar referências simbólicas, contribui para impedir que as formações fraternas se tornem agrupamentos identitários com sua marca inevitável de intolerância e fanatismo, expressões conhecidas do horror à alteridade, isto é, à castração" (Kehl, 2000, p. 243, destaque da autora).

8. Série do cinema hollywoodiano, iniciada em 1998, que chegou ao número 5 em 2006, sempre com uma bilheteria extraordinária, em vários países do mundo. A temática é a vida de jovens de classe média norte-americana. Ver, a propósito, a análise desse tipo de filmes em Shary (2005).

9. A pesquisadora se refere aos dados de pesquisas feitas no Brasil e em outros países, como Canadá e Portugal, a respeito de temas como a participação social da juventude, entre outros, publicados no livro Juventude contemporânea: perspectivas nacionais e internacionais (Castro \& Correa, 2005).

Educ. Soc., Campinas, vol. 29, n. 104 - Especial, p. 667-686, out. 2008

Disponível em <http://www.cedes.unicamp.br> 


\section{Referências}

ABRAMO, H.W.; BRANCO, P.P.M. (Org.). Retratos da juventude brasileira: análise de uma pesquisa nacional. São Paulo: Fundação Perseu Abramo; Instituto Cidadania, 2005.

ARENDT, H. A condição humana. Rio de Janeiro: Forense Universitária, 2000.

BAUMAN, Z. La sociedad individualizada. Madrid: Cátedra, 2001.

BENJAMIN, W. Teses sobre o conceito de história. In: Benjamin, W. Sobre arte, técnica, linguagem e politica. Lisboa: Relógio D'água, 1992. p.157-170.

BERGSON, H. Matéria e memória. São Paulo: Martins Fontes, 1990.

BOSI, E. Memória e sociedade: lembranças de velhos. 2. ed. São Paulo: T.A. Queiroz; EDUSP, 1987.

BUCCI, E.; KEHL, M.R. Videologias. São Paulo: Boitempo, 2004.

CANCLINI, N.G. Ser diferente é desconectar-se?: sobre as culturas juvenis. In: Canclini, N.G. Diferentes, desiguais e desconectados: mapas da interculturalidade. Rio de Janeiro: UFRJ, 2005.

CASTRO, L.R.; CORREA, J. (Org.). Juventude contemporanea: perspectivas nacionais e internacionais. Rio de Janeiro: Nau; FAPERJ, 2005.

CHAUÍ, M. Prefácio. In: Bucci, E.; KeHL, M.R. Videologias. São Paulo: Boitempo, 2004. p. 7-13.

COSTA, J.F. A ética e o espelho da cultura. Rio de Janeiro: Rocco, 1994.

DELEUZE, G. Bergsonismo. Rio de Janeiro: Editora 34, 1999.

DERRIDA, J.; ROUDINESCO, E. De que amanhã... diálogo. Rio de Janeiro: Zahar, 2004.

DIDI-HUBERMAN, G. O que vemos, o que nos olha. Rio de Janeiro: Editora 34, 1998.

DIDI-HUBERMAN, G. Imágens pese a todo: memória visual del Holocausto. Trad. de Mariana Miracle. Barcelona: Paidós, 2004. 
ECO, U. A misteriosa chama da Rainha Loana. Trad. de Eliana Aguiar. Rio de Janeiro: Record, 2005.

FISCHER, R.M.B. Foucault e a análise do discurso em educação. Cadernos de Pesquisa, São Paulo, n. 114, p. 197-223, nov. 2001.

FISCHER, R.M.B. Mídia, juventude e educação: modos de construir o "outro" na cultura. Arquivos Analíticos de Políticas Educativas, v. 16, n. 2, 2008. Disponível em: <http://epaa.asu.edu/epaa/v16n2>. Acesso em: 20 jul. 2008.

FOUCAULT, M. A pintura fotogênica. In: Foucault, M. Estética: literatura e pintura, música e cinema. Rio de Janeiro: Forense Universitária, 2001. p. 346-355. (Ditos e escritos, v. 3)

GARBER, M. Symptoms of culture. London: Penguin, 1999.

HUYSSEN, A. Memórias do modernismo. Rio de Janeiro: UfRJ, 1997.

HUYSSEN, A. Seduzidos pela memória: arquitetura, monumentos e mídia. Rio de Janeiro: Aeroplano, 2000.

KEHL, M.R. A fratria órfã: o esforço civilizatório do rap na periferia de São Paulo. In: Kehl, M.R. (Org.). Função fraterna. Rio de Janeiro: Relume-Dumará, 2000. p. 209-244.

KEHL, M.R. Juventude como sintoma da cultura. In: NoAVEs, R.; VAnnuchi, P. (Org.). Juventude e sociedade: trabalho, educação, cultura e participação. São Paulo: Perseu Abramo, 2005. p. 89-113.

KEHL, M.R. Os excessos do imaginário. Folha de S. Paulo, São Paulo, 18 jan. 2004. Caderno Mais!, p. 12.

LECCARDI, C. Para um novo significado do futuro: mudança social, jovens e tempo. Tempo social, São Paulo, v. 17, n. 2, 2005. Disponível em: <http://www.scielo.br/scielo.php?script=sci_arttext $\&$ pid=S0103 $20702005000200003 \& \operatorname{lng}=$ pt\&nrm=iso >. Acesso em: 2 jul. 2007.

MARCELLO, F.A. Cinema e educação: da criança que nos convoca à imagem que nos afronta. In: REUNIÃO ANUAL DA ANPED, 29., 2007, Caxambú. Anais... Caxambú: Anped, 2007. Disponível em: <http://www.anped.org.br/reunioes/29ra/trabalhos/trabalho/GT162480-Int.pdf>. Acesso em: 30 jul. 2008. 
ORTEGA, F. Para uma politica da amizade: Arendt, Derrida, Foucault. Rio de Janeiro: Relume-Dumará, 2000.

SARLO, B. Cenas da vida pós-moderna: intelectuais, arte e videocultura na Argentina. Rio de Janeiro: UfRJ, 1997a.

SARLO, B. Paisagens imaginárias. São Paulo: Edusp, $1997 \mathrm{~b}$.

SKLIAR, C. Pedagogia (improvável) da diferença: e se o outro não estivesse aí? Rio de Janeiro: DP\&A, 2003.

SHARY, T. Teen movies: American youth on screen. Londres: Wallflower, 2005.

SILVERSTONE, R. Tecnologias. In: Silverstone, R. Por que estudar a midia? São Paulo: Loyola, 2002. p. 45-62.

ZIZEK, S. A paixão pelo real (Entrevista a Vladimir Safatle). Folha de S. Paulo, São Paulo, 30 nov. 2003a. Caderno Mais!, p. 6-7.

ZIZEK, S. Bem-vindo ao deserto do real. São Paulo: Boitempo, 2003 b. 